\title{
A SEA ICE TERRAIN MODEL AND ITS APPLICATION TO SURFACE VEHICLE TRAFFICABILITY
}

\author{
W.D. Hibler III and S.F. Ackley
}

December 1973

\author{
PREPARED FOR \\ ADVANCED RESEARCH PROJECTS AGENCY \\ ARPA ORDER 1615 \\ BY \\ CORPS OF ENGINEERS, U.S. ARMY
}

COLD REGIONS RESEARCH AND ENGINEERING LABORATORY

HANOVER, NEW HAMPSHIRE 


\section{PREF ACE}

This report was prepared by Dr. W.D. Hibler III, Research Physicist, and Mr. S.F. Ackley, Research Physicist, of the Snow and Ice Branch, U.S. Army Cold Regions Research and Engineering Laboratory (USA CRREL).

The study was conducted in support of the Advanced Research Projects Agency (ARPA) Arctic Surface Effect Vehicle Program under ARPA Order 1615.

The report was technically reviewed by Mr. S.J. Mock and Dr. R.A. Liston of USA CRREL.

Manuscript received 27 September 1973. 


\section{CONTENTS}

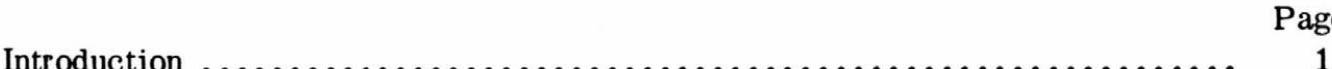

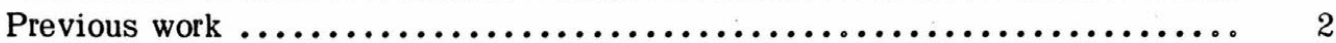

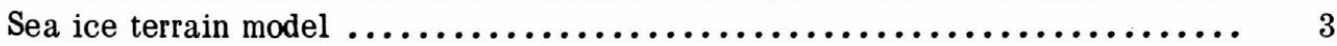

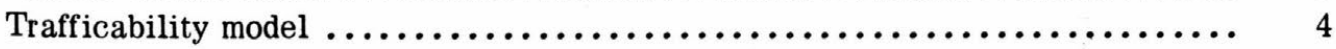

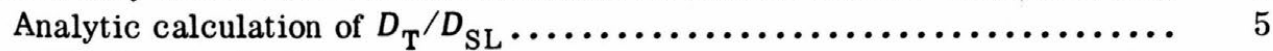

Monte Carlo calculation .................................... 6

Results of trafficability computations ...................... 7

Experimental trafficability ratios using ridge overlays............. 7

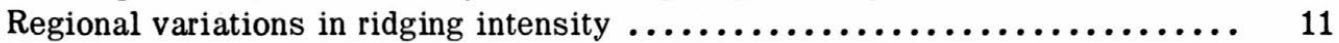

Additional trafficability aspects of sea ice $\ldots \ldots \ldots \ldots \ldots \ldots \ldots \ldots \ldots \ldots \ldots . \quad 14$

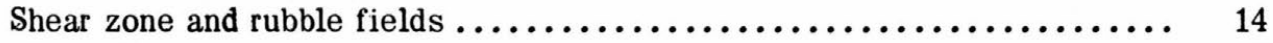

Linear lead systems ................................. 17

Conclusions .......................................... 17

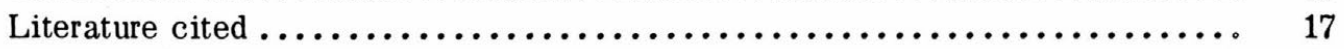

Appendix A. Distribution of the lateral extent of ridges ................ 19

Abstract ................................................... 21

\section{ILLUSTRATIONS}

Figure

1. Ground view of "first year" pressure ridge in the Beaufort Sea, 1971... 1

2. Trafficability ratio $D_{\mathrm{T}} / D_{\mathrm{SL}}$ as a function of $\left.\mu_{\mathrm{h}}\left(<L^{2}\right\rangle\right) /(<L>) \ldots \ldots \ldots \quad 7$

3. Ridges prepared from an aerial photo mosaic overlay of sea ice (site of March-April 1972 AIDJEX camp)..................... 8

4. Ridges prepared from an aerial photo mosaic overlay of sea ice (site of

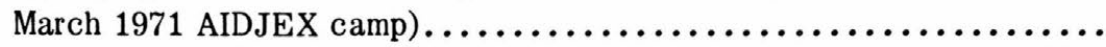

5. Ridge model prepared from Figure 4, with the addition of a set of random ridges having the same length distribution as those shown in Figure 4.9

6. Vertical aerial view of sea ice showing the intersecting nature of ridges. $\quad 10$

7. Regional variation of ridging in the Arctic Basin, given in terms of number of ridges per kilometer above different heights........... 12

8. Multiyear approximately 7-ft-high ridge in the Beaufort Sea.......... 12

9. Small first-year ( 5 -ft-high) ridge in the Beaufort Sea $\ldots \ldots \ldots \ldots \ldots \ldots . \ldots 13$

10. First-year (7 to 8-ft-high) ridge in the Beaufort Sea .............. 13

11. Trafficability ratio $D_{\mathrm{T}} / D_{\mathrm{SL}}$ as a function of vehicle clearance ability for various zones of the Arctic Basin ....................... 14

12. Oblique aerial view of the shear zone off Barrow, Alaska ........... 15

13. Closeup view of a rubble field in the Beaufort Sea .............. 15

14. Aerial photo of typical linear lead system in sea ice .............. 16

\section{TABLES}

\section{Table}

I. Comparison of predicted and observed trafficability ratios 


\title{
A SEA ICE TERRAIN MODEL AND ITS APPLICATION TO SURFACE VEHICLE TRAFFICABILITY
}

by

\author{
W.D. Hibler III and S.F. Ackley
}

\section{Introduction}

It is well known that the arctic pack ice presents a formidable surface for any vehicle traveling at high speed. The primary obstacles to the movement of amphibious surface vehicles such as a surface effect vehicle are pressure ridges, which reach heights as great as $20 \mathrm{ft}$, and often are several kilometers long. A typical example of a pressure ridge is shown in Figure 1, which gives a ground view of a "first-year" pressure ridge 7 to $8 \mathrm{ft}$ high.

The statistical occurrence and height distribution of pressure ridges have been the subjects of several recent studies (Hibler et al. 1972, Mock et al. 1972, Weeks et al. 1971). In addition, considerable progress has been made in estimating the ridging characteristics of the Arctic Basin, using laser profilometry data (Hibler et al. in prep). For classifying pressure ridges, theoretical ridge height and spacing probability density functions have been derived which have been found to be in good agreement with extensive submarine sonar (Hibler et al. 1972) and laser profilometer (Hibler et al. in prep) data. Using these theoretical ridge height and spacing probability density functions, it has been found that by considering ridges to be composed of short "ridge links" the

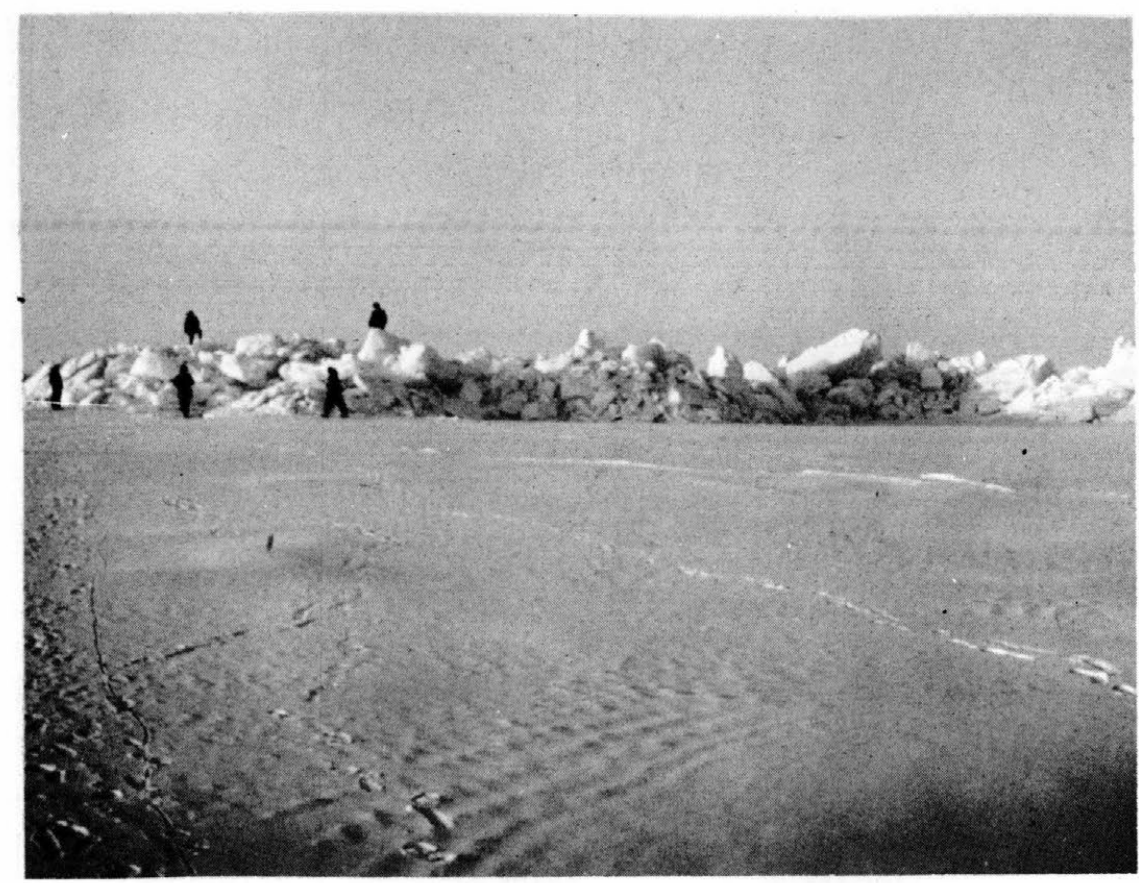

Figure 1. Ground view of "first year" pressure ridge in the Beaufort Sea, 1971. 
ridge characteristics of a given region may be well defined by two parameters: the mean ridge height $\bar{h}$ and the ridge density $R_{\mathrm{D}}$, which is defined as the total length of ridging per unit area. Furthermore, it has been shown (Mock et al. 1972) that for randomly oriented ridges $R_{\mathrm{D}}$ is given by $(\pi / 2) \mu$ where $\mu$ is the number of ridges per unit length intersected by a straight-line path. Consequently, by using digital filtering techniques, $\bar{h}$ and $R_{\mathrm{D}}$ may be obtained remotely from laser profile data (Hibler 1972). The final information needed to characterize a ridging system in three dimensions is the distribution of the lateral extents of ridges. We have recently obtained estimates of this parameter; the results are reported in the Appendix.

Using these statistical distribution models, a realistic three-dimensional ridge model for sea ice terrain was constructed in this study. Using this model, and assuming a vehicle height clearance ability, a trafficability analysis was performed by calculating the ratio of the total distance traveled $D_{\mathrm{T}}$ to the component of distance traveled along the desired travel direction $D_{\mathrm{SL}}$. The resulting trafficability ratios, denoted by $D_{\mathrm{T}} / D_{\mathrm{SL}}$ as well as other parameters, give an estimate of transit times and fuel consumption as a function of ridging parameters and provide a basis for more detailed mobility analysis, using information on maneuverability, obstacle avoidance systems, and fuel consumption rates as a function of speed. Good agreement was found between trafficability ratios calculated from the model and those determined from simulated routes through sea ice areas obtained from aerial photo mosaics.

For application of this sea ice terrain model and trafficability analysis, the regional variation in ridging intensity in the Arctic Basin, based upon analysis of laser profilometer data, is discussed in this report. In particular, the number of ridges per kilometer above a given height for different regions and different heights is discussed. This is a key parameter in the trafficability model and allows estimation of the ease or difficulty of motion of vehicles having a given clearance ability in different regions of the Arctic.

Finally, certain other aspects and ramifications of the pack ice terrain relating to amphibious vehicle mobility are discussed, with emphasis on: 1) the nature of the shear zone formed in the offshore region, which forms a rugged but relatively thin barrier to travel; and 2) the presence of long linear leads which occur during dilation of the pack ice in strong weather systems and which form effective high-speed, flat, parallel "highways" for amphibious vehicle travel.

\section{Previous Work}

Most trafficability and mobility studies over sea ice terrain to date have treated the terrain in a simplified manner by considering it to be an isotropic two-dimensional grid of point obstacles. Typically, the differential height from one point to another is calculated, using a multivariate distribution function based upon spectral densities of the surface roughness. Examples of such studies are a detailed treatment by Smith and Nakano (1973), and less detailed discussions by Grumman Aerospace Corp. (1972) and LeSchack and Long (1972).

Although useful for Monte Carlo calculations, such models appear to bear little resemblance to an actual sea ice terrain. The reasons for this are twofold. The first and basic reason is that, although sea ice terrain may be isotropic on a large scale (say $30 \mathrm{~km}$ ), it is certainly not isotropic locally because ridges are generally linear features sometimes extending several kilometers. Consequently, once an impassable ridge is encountered, the vehicle must go around it to proceed. Simply stated, the ridge may not be treated as a point obstacle.

The second reason is that an isotropic, multivariate, normal distribution function does not provide an adequate description of sea ice terrain. Although such a description is useful for isotropic Gaussian stationary terrain, it is not useful for sea ice, which appears to be very anisotropic on the local level, with a distribution of ice heights much closer to lognormal (Hibler and 
Mock 1971) than Gaussian. Certainly the local anisotropy, as discussed above, is a problem because, although an autocovariance along a given straight-line path across the terrain may indicate no correlation between points $100 \mathrm{~m}$ apart, points along the crest of a ridge persist in height for hundreds of meters.

Apart from isotropy problems, the probability of obstacle encounters calculated by such functions appears physically unrealistic. Smith and Nakano (1973), for example, estimate from a typical spectral density that a 2-ft-high obstacle occurs with a 0.0005 probability over a 40 -ft interval, or about one 2 -ft-high obstacle every 8 miles. Since laser profile data indicate that a 2 -fthigh obstacle typically occurs at spacings of $300 \mathrm{ft}$, the Smith and Nakano predictions are certainly unrepresentative. Therefore, as a rule, although obstacle heights might be calculated from spectral densities by making certain assumptions (Cartwright 1962), such uses of sea ice spectral densities appear unjustified at present.

A more realistic way of producing a terrain model, which has been discussed by AerojetGeneral Corp. (1972), is to construct random ridge heights and spacings generated according to height and spacing distribution models [developed by Hibler et al. (1972)] along a given path, and then to calculate the average detour lengths using an average ridge extent. Such model calculations, although of considerable usefulness for low ridge densities, are not valid for high ridge densities because the model does not take into account ridge intersections. For high ridge densities, there are a large number of such ridge intersections and cul-de-sacs which make the detours very long and which must therefore be taken into account.

The model developed in this study not only takes into account intersecting ridges but also. recognizes the peculiarities of the sampling problem; for example, given ridges of equal length, a vehicle selectively encounters the ridges nearly prependicular to its path more often than it does those approximately parallel to its path. Also, given ridges of similar orientation, but different lengths, a vehicle encounters the longer ridges more frequently than it does the shorter ones. In a complete trafficability.calculation, these factors must be included and, as is shown later, they do have important ramifications.

\section{Sea Ice Terrain Model}

The basic defect with most sea ice trafficability studies to date has been the unrealistic sea ice terrain models used. Consequently, the emphasis in this study has been to develop a realistic three-dimensional sea ice obstacle model which, although making trafficability calculations more difficult, is a reasonable representation of the actual terrain. To create such a model, we assume the following characteristics based upon ridge statistical studies.

1. The distribution of pressure ridge heights above some arbitrary cutoff height $h_{0}$ is given by the probability $P$ density function (Hibler et al. 1972):

$$
P(h) d h=2\left(\frac{\lambda}{\pi}\right)^{1 / 2} \frac{\exp \left(-\lambda h^{2}\right) d h}{\operatorname{erfc}\left(\sqrt{\lambda} h_{0}\right)}
$$

where

$$
\begin{aligned}
P(h) d h & =\text { the fraction of ridges with heights between } h \text { and } h+d h \\
\text { erfc } & =\text { the complementary error function } \\
\lambda & =\text { the shape parameter which is determined uniquely by } \bar{b} \text {, the mean ridge height. }
\end{aligned}
$$

[Shape parameters for different regions of the Arctic Basin are given by Hibler et al. (in prep).] 
2. The probability of occurrence of ridges along a linear path is given by a Poisson distribution (Hibler et al. 1972). Consequently, the spacing distribution is a negative exponential and both it and the occurrence distribution are well described by $\mu$, the average number of ridges per kilometer.

3. The orientation of ridges is assumed to be random (Mock et al. 1972); that is, for a given area there are approximately equal lengths of ridges oriented at any angle. As a corollary to this, it can be shown that the ridge density $R_{\mathrm{D}}$ (total length of ridges per square kilometer) is related to $\mu$ along a linear path by $R_{\mathrm{D}}=(\pi / 2) \mu$.

4. The linear extent of a ridge before an appreciable hole occurs in it is described by some distribution function $P_{L}(L) d L$, with first and second moments $\langle L\rangle$ and $\left\langle L^{2}\right\rangle$. This function must be estimated from aerial photo mosaics; and as a first approximation, we assume that $P_{\mathrm{L}}(L)$ is approximately independent of ridge height for ridges higher than $5 \mathrm{ft}$ and is negative exponential in form. An estimation of $P_{L}(L)$ from pressure ridge data is given in the Appendix.

5. All the distribution functions are assumed to be independent; for example, if a high ridge is crossed there is no preferred probability that the next ridge crossed will also be high (or low). This has been tested to some extent (Hibler and Mock 1971).

Based on these characteristics, a typical sea ice obstacle model could be created in the following conceptual manner. First a "box" of random ridges could be created using the height distribution $P(h) d h$ and the length distribution $P_{L}(L) d L$. Then, taking a two-dimensional region, a number of these random (random both in $x$ and $y$ coordinates and in orientation) ridges would be placed on the surface until the total length of ridges equaled the desired ridge density $R_{\mathrm{D}}$.

Certain qualifications to the above model should be noted. One qualification is that a profile along a ridge rapidly varies in height. Consequently, although the use of the lateral extent distribution is reasonably valid for larger vehicles, small vehicles such as snowmobiles may be able to slip through a ridge at many locations because of small holes in the ridge. This is discussed in somewhat more detail by Hibler and Ackley (1973).

Another point is the variation of $P_{L}(L) d L$ for different ridge heights. Since such variations may occur, trafficability analyses should generally provide for determining the sensitivity to changes in $P_{L}(L) d L$. The assumption of random orientation is also one that, although reasonable over large areas (tens of kilometers), breaks down over small areas (several kilometers) where ridges often seem to occur in a linear pattern (Hibler 1971, Mock et al. 1972). The height and spacing distributions, however, do appear to be valid for all ridging systems.

\section{Trafficability Model}

To carry out a simple trafficability calculation, we will consider a completely maneuverable vehicle that can clear any ridge up to a height $h$. We will then calculate the ratio of the total distance traveled to the component of distance in a desired direction. This ratio $D_{\mathrm{T}} / D_{\mathrm{SL}}$ turns out to be a unique function of the number of ridges per unit length higher than $h$, denoted by $\mu_{\mathrm{h}}$, and of the first and second moments $\left(\langle L\rangle\right.$ and $\left.\left\langle L^{2}\right\rangle\right)$ of the ridge extent distribution function. Consequently, using statistics compiled from laser profile data, the $D_{\mathrm{T}} / D_{\mathrm{SL}}$ ratios may be estimated for different regions of the Arctic.

First, an analytic calculation with ridge intersection neglected is performed. This analytic calculation is similar to that discussed by Bekker (1969) with extensions to include obstacles of different lengths. This calculation is useful for illustrating how the sampling biasing affects the results; i.e., long ridges perpendicular to the desired motion are encountered more frequently than short ones. Then the basic calculation for $D_{\mathrm{T}} / D_{\mathrm{SL}}$ is performed, using a Monte Carlo method which 
takes into account cul-de-sacs and ridge intersections. The point at which the results obtained with the Monte Carlo method approach those obtained with the analytic model is also important since it indicates at what point ridge intersection problems become negligible. In general, as might be expected, the results indicate that $D_{\mathrm{T}} / D_{\mathrm{SL}}$ very rapidly increases as ridge intersections begin to be encountered.

\section{Analytic calculation of $D_{\mathrm{T}} / D_{\mathrm{SL}}$}

Consider an area of dimensions $W$ by $W$ with $N$ ridges higher than $h$ dispersed randomly throughout in both orientation and direction. The lengths of the ridges are such that there is a probability $P_{L}(L) d L$ of a ridge having a length between $L$ and $L+d L$. We consider that a desired vehicle path begins at the bottom of the area and proceeds north. We neglect lateral offset because of the random orientation of ridges. The probability that any given ridge intersects the vehicle's path is given by:

$$
\frac{L P_{\mathrm{L}}(L) d L}{W \pi}|\sin \theta| d \theta
$$

where $\theta(-\pi / 2 \leq \theta \leq \pi / 2)$ is the angle of the ridge relative to north. For each ridge of length $L$ and orientation $\theta$, the vehicle, on the average, travels an additional distance $L / 2(1-\cos \theta)$ going around the ridge. Summing over all ridges in the area and over all angles, we have the extra distance $\Delta D$ :

$$
\begin{aligned}
\Delta D & =\frac{N}{2 W \pi} \int_{0}^{\infty} P_{\mathrm{L}}(L) L^{2} d L \int_{-\pi / 2}^{\pi / 2}(1-\cos \theta)|\sin \theta| d \theta \\
& =\frac{N}{W \pi}<L^{2}>\int_{0}^{\pi / 2}(\sin \theta-\sin \theta \cos \theta) d \theta \\
& =\frac{N<L^{2}>}{2 \pi W} .
\end{aligned}
$$

However, the total number of ridges intersecting the vehicle path is:

$$
\begin{aligned}
\mu_{\mathrm{h}} & =\frac{N}{W_{\pi}} \int_{0}^{\infty} L P_{\mathrm{L}}(L) d L \int_{-\pi / 2}^{\pi / 2}|\sin \theta| d \theta \\
& =\frac{2 N<L>}{W_{\pi}} .
\end{aligned}
$$

Therefore, the total distance traveled over the straight-line distance is

$$
\begin{aligned}
\frac{D_{\mathrm{T}}}{D_{\mathrm{SL}}} & =\frac{W+\Delta D}{W}=\frac{\left.N<L^{2}\right\rangle}{2 \pi W^{2}}+1 \\
& =\frac{1}{4} \frac{\left\langle L^{2}\right\rangle}{\langle L\rangle} \mu_{\mathrm{h}}+1
\end{aligned}
$$

where $\mu_{\mathrm{h}}$ is the number of ridges per unit length with height greater than $h$ encountered along a straight-line path. 
The most striking aspect of the analytic result is that the trafficability ratio $D_{\mathrm{T}} / D_{\mathrm{SL}}$ depends on the distribution of ridge lengths only through the ratio of the second moment to the first moment. Also, the factor $\left\langle L^{2}\right\rangle /\langle L\rangle$ only appears linearly, so that small changes in $P_{L}(L)$ are not extremely critical in determining mobility; this is certainly an advantage since $P_{L}(L)$ is a difficult distribution function to estimate exactly for sea ice.

\section{Monte Carlo calculation}

Clearly the primary defect in the analytic approach is the neglect of ridge intersections. In order to determine the effect of such intersections on trafficability, as well as to verify the analytic model, a Monte Carlo calculation was performed. The calculation proceeded by the following steps.

1. A set of random ridges that would be encountered along a straight-line path was constructed. The number of random ridges having a given orientation $\theta$ and length $L$ were weighted by a factor $L \cos \theta$ where $\theta$ is the angle between the ridge and the straight-line path. This factor takes into account the increased probability of encountering longer ridges nearly perpendicular to the path of motion. The distribution of ridge lengths was taken to be a negative exponential and was constructed so that $\left\langle L^{2}\right\rangle /\langle L\rangle=1.6 \mathrm{~km}$.

2. Using small increments $\Delta X$, we proceeded along a desired straight-line, searching randomly for a ridge in each increment according to an input ridge frequency $\mu_{\mathrm{h}}$ (number of ridges per kilometer above height $h$ ).

3. If no ridge was encountered, the desired distance and total distance traveled were increased by $\Delta \boldsymbol{X}$.

4. If a ridge was encountered, the vehicle heading was changed to be parallel to the random ridge of length $L$ at direction $\theta$ so that the vehicle still had a forward component of motion.

5. The point at which the ridge was encountered (and thus the distance to go around the ridge) was randomly selected.

6. We then proceeded in $\Delta X$ increments at a heading $\theta$, recording after each increment a total distance of $\Delta X$ and a desired distance of $(\cos \theta) \Delta X$. In each increment, a random check for other ridges was made.

7. If the end of the ridge was reached before another ridge was encountered, the heading was changed to $\theta=0$ and we returned to step 2 and proceeded as before.

8. If another ridge at direction $\theta^{\prime}$ was encountered while $\theta \neq 0$ (i.e. while we. were still going around the first ridge), we declared a cul-de-sac and changed the heading of the vehicle to direction $\theta^{\prime}$ (or $-\theta^{\prime}$ ) so that the vehicle had a backward component of motion. We then proceeded as in step five.

9. The program ended once the total distance $D_{\mathrm{T}}$ reached a desired value. The straight line or desired distance $D_{\mathrm{SL}}$ is always less than or equal to $D_{\mathrm{T}}$.

10. The resulting $D_{\mathrm{T}} / D_{\mathrm{SL}}$ ratio and number of cul-de-sacs were recorded as a function of the dimensionless parameter $\mu_{\mathrm{h}}\left\langle L^{2}\right\rangle /\langle L\rangle$. It is easy to see that $D_{\mathrm{T}} / D_{\mathrm{SL}}$ is a unique function of this parameter by dimensional analysis.

One of the more important steps in the Monte Carlo computation is step 8, which takes into account the effects of intersecting ridges. The procedure used does not account exactly for such intersections, but simply declares that the vehicle must have a backward component of motion after encountering a ridge intersection; i.e. it must proceed along a ridge so that it has a negative component of motion in the desired direction. This approximate procedure gives a slightly high estimate of the extra distance traveled but is a reasonable first approximation commensurate with the accuracy 


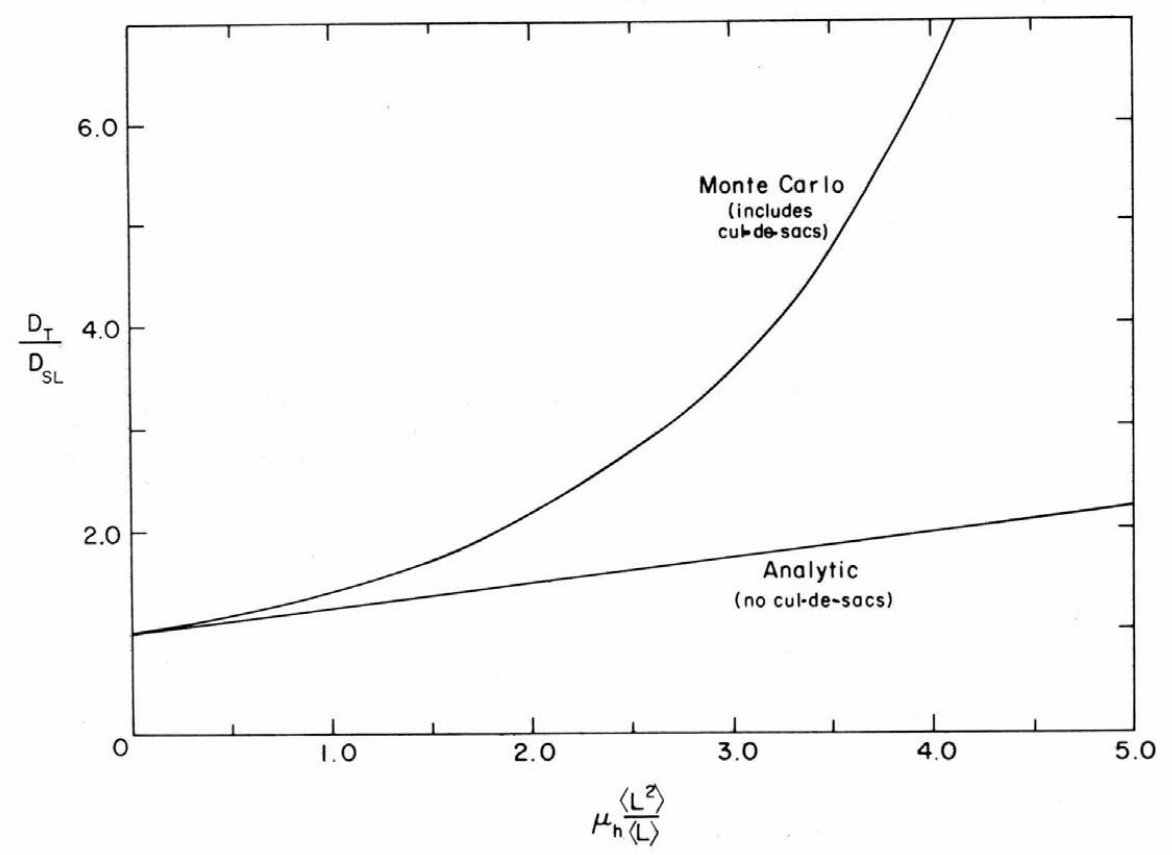

Figure 2. Trafficability ratio $D_{\mathrm{T}} / D_{\mathrm{SL}}$ as a function of $\mu_{\mathrm{h}}\left(<L^{2}>\right) /(<L>)$. $\mu_{\mathrm{h}}=$ number of impassable ridges $/ \mathrm{km},\langle L\rangle=$ tirst moment of the ridge length distribution, and $\left\langle L^{2}\right\rangle=$ second moment of the ridge length distribution.

of the terrain model. Also, in practice, since the extra distance traveled rises very rapidly as more cul-de-sacs are encountered, a qualitative estimate of the extra distance is adequate for most trafficability purposes.

Note also that, similarly to the analytic result, the trafficability ratio $D_{\mathrm{T}} / D_{\mathrm{SL}}$ depends only on $\mu_{\mathrm{h}}\left\langle L^{2}\right\rangle /\langle L\rangle$, so that uncertainties in the exact moments of the distribution of the ridge lengths may not be critical.

\section{Results of trafficability computations}

Random simulations were made using the Monte Carlo computer program described above with a total distance for each simulation of $100 \mathrm{~km}$. For each value of the ridge frequency $\mu_{\mathrm{h}}$ (and hence each value of the parameter $\mu_{\mathrm{h}}\left\langle L^{2}\right\rangle /\langle L\rangle$ ), six random simulations were performed. For each simulation the trafficability ratio $D_{\mathrm{T}} / D_{\mathrm{SL}}$ was recorded, and average results of the six independent simulations were computed for each value of $\mu_{\mathrm{h}}$. The results, as a function of $\mu_{\mathrm{h}}\left\langle L^{2}\right\rangle /\langle L\rangle$, are shown in Figure 2.

As can be seen from Figure 2, the effect of cul-de-sacs forces the trafficability ratio up rapidly. Since typical values of $\left\langle L^{2}\right\rangle /\langle L\rangle$ are of the order of $1.5 \mathrm{~km}$, the results indicate that, for more than 2 impassable ridges $/ \mathrm{km}$, movement becomes rather tortuous, although possible, up to about 3 ridges $/ \mathrm{km}$. The other important limiting case is the point at which the analytic approximation approaches the Monte Carlo result. From Figure 2, this would appear to be reasonably valid for $\mu_{\mathrm{h}}<L^{2}>/<L><1$ or for the presence of less than about 0.5 impassable ridges $/ \mathrm{km}$.

\section{Experimental trafficability ratios using ridge overlays}

In order to test the trafficability calculations experimentally, ridge overlays of two different regions of the Arctic were prepared using aerial photo mosaics with typical routing paths drawn 


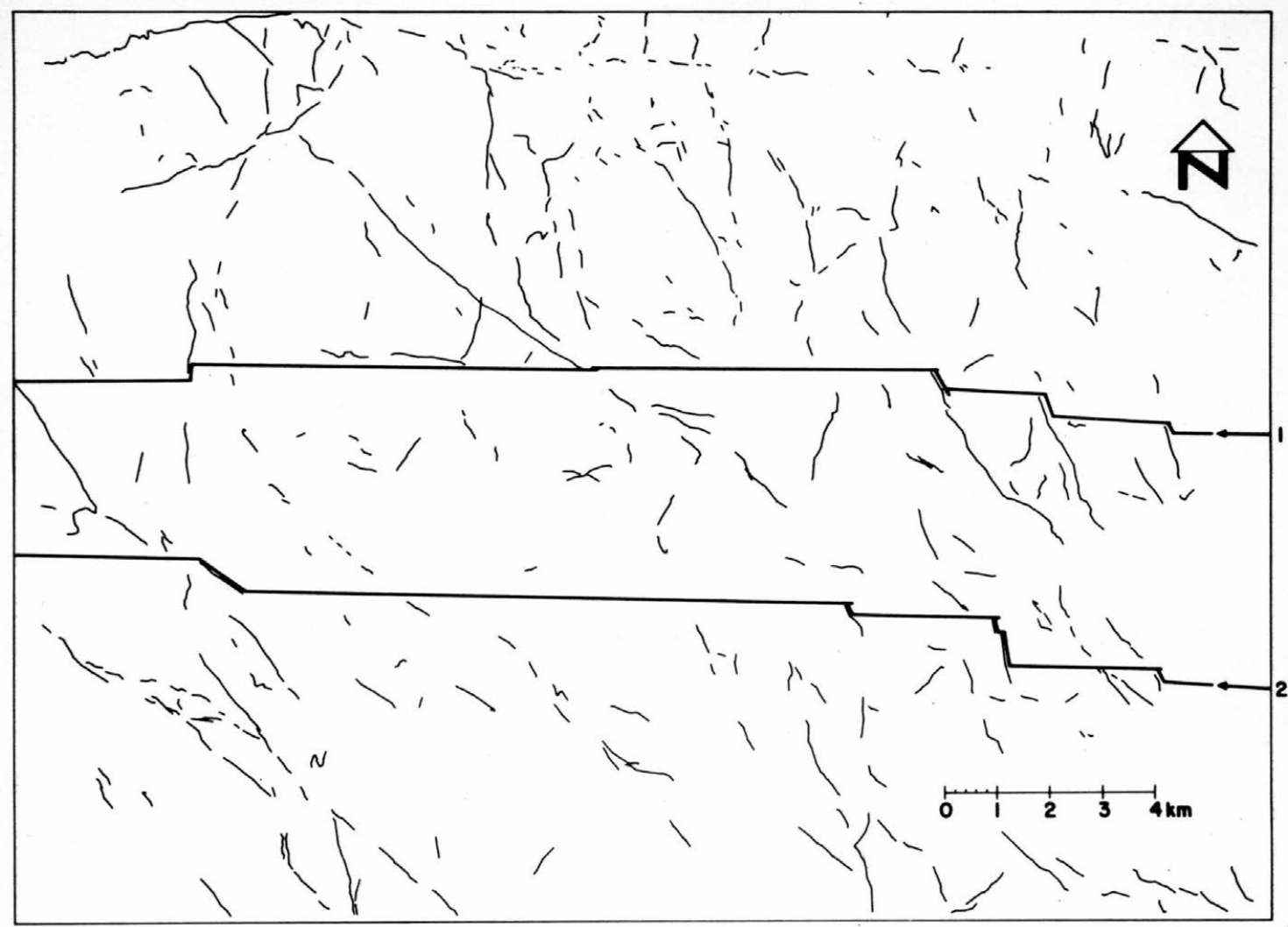

Figure 3. Ridges prepared trom an aerial photo mosaic overlay of sea ice. Simulated vehicle routings are indicated by solid lines with arrows. (Site of March-April 1972 AIDJEX camp.)

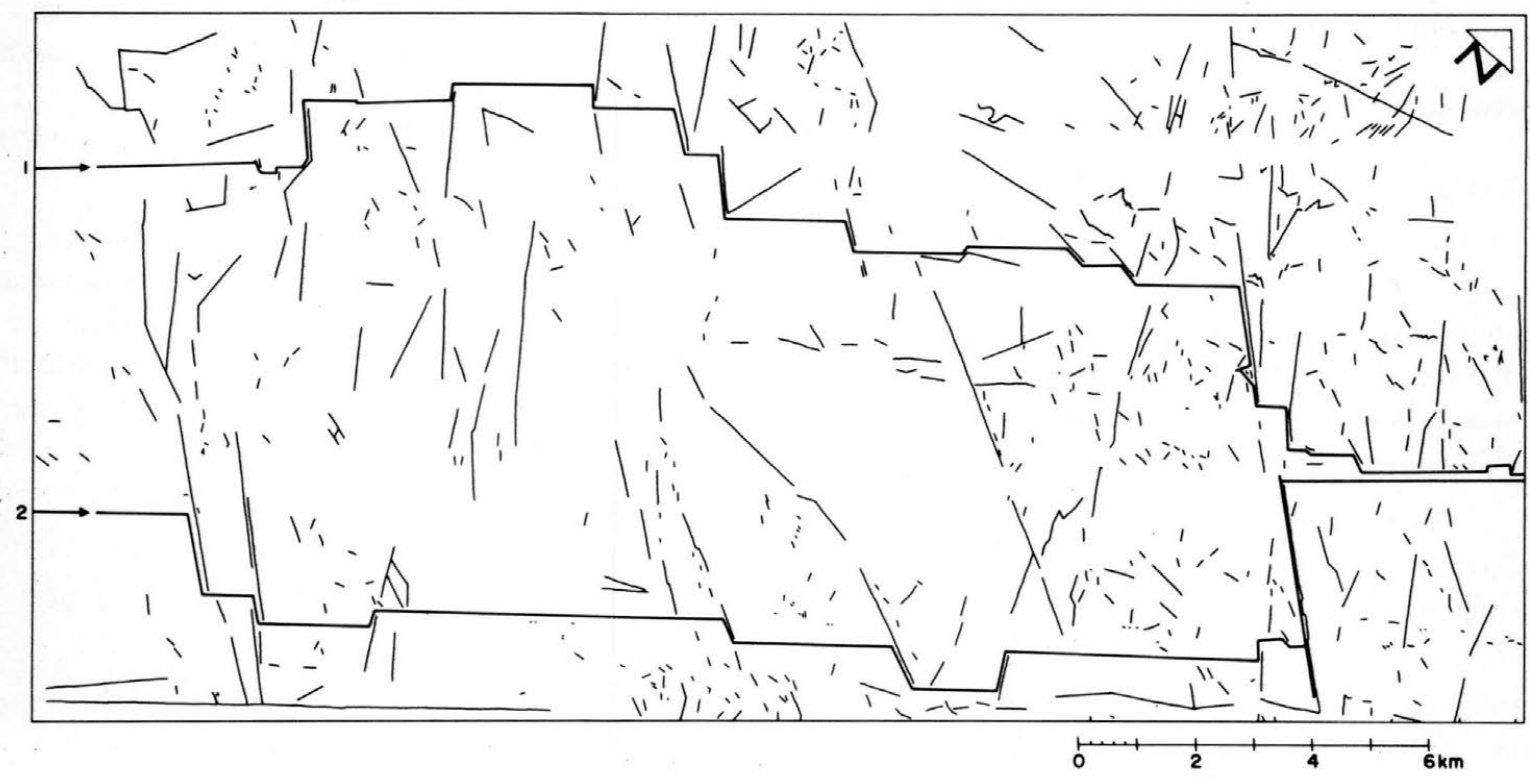

Figure 4. Ridges prepared from an aerial photo mosaic overlay of sea ice. Simulated vehicle routings are indicated by solid lines with arrows. (Site of March 1971 AIDJEX camp.) 


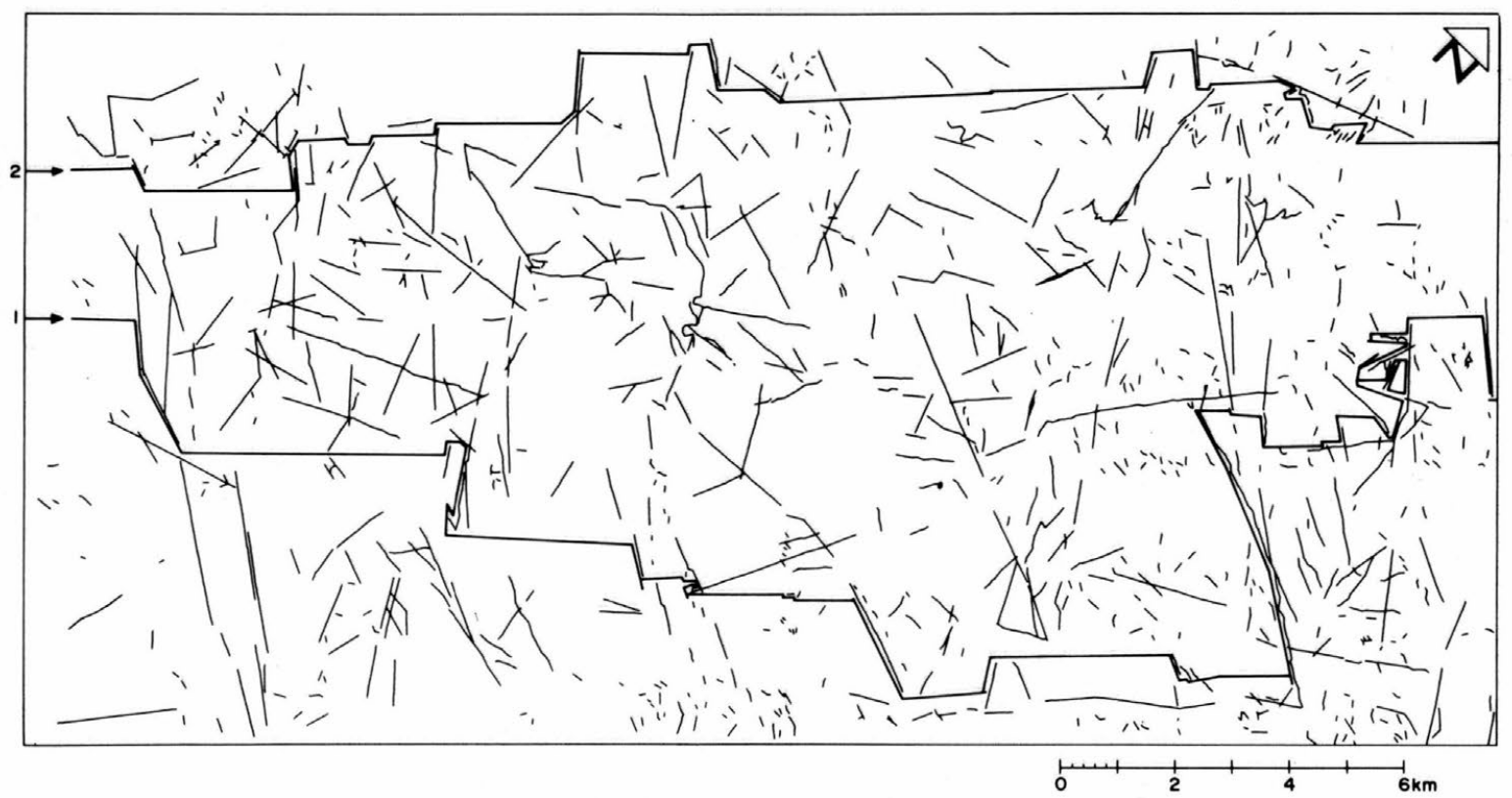

Figure 5. Ridge model prepared from Figure 4, with the addition of a set of random ridges having the same length distribution as those shown in Figure 4. Simulated routing paths are shown by solid lines with arrows.

through them from which trafficability ratios were calculated; the results were compared with predicted results based on the average ridge frequency $\mu_{\mathrm{h}}$ of the photo mosaics. The overlays were also used to estimate the nature of the distribution of ridge lengths as discussed in the Appendix. The overlays were prepared by using photo mosaics from which dominant ridges were outlined. Although there was considerable approximation, this procedure supplied a qualitative measure of ridges above $5 \mathrm{ft}$ high, especially since shadows might be used to estimate ridge height.

Figures 3 and 4 illustrate two ridge overlays with typical routing paths constructed. The ridge frequencies were $0.31 / \mathrm{km}$ for Figure 3 and $0.65 / \mathrm{km}$ for Figure 4 . In addition to these two photo mosaics, a photo mosaic having a higher ridge density was constructed by adding a set of random ridges to the mosaic in Figure 4 having the same length distribution as the ridges in Figure 4. This constructed overlay, with a ridge frequency of $1.06 / \mathrm{km}$ is shown in Figure 5 .

Besides the routings drawn on the photo mosaics in Figure 5, several other routings were also constructed on each photo mosaic and average trafficability ratios were computed. A comparison of these experimental trafficability ratios with predicted ratios based on the Monte Carlo calculation and our estimated values of $\mu_{\mathrm{h}}$ and $\left\langle L^{2}\right\rangle \mid\langle L\rangle$ is given in Table I. The predicted and observed results are in reasonable agreement, with the observed ratios generally being slightly smaller than the predicted values. Since, as discussed earlier, the Monte Carlo calculation tends to slightly overestimate the trafficability ratio, this type of deviation is not unexpected and might be particularly pronounced when the ridges have a definite lineation, which may have occurred in Figure 4.

Table I. Comparison of predicted and observed trafficability ratios.

\begin{tabular}{ccccc}
$\begin{array}{c}\text { Photo } \\
\text { mosaic }\end{array}$ & $\mu_{\mathrm{h}}$ & $\left\langle L^{2}\right\rangle\langle\langle L\rangle$ & $\left\langle D_{\mathrm{T}} / D_{\mathrm{SL}}\right\rangle$ observed & $\begin{array}{c}D_{\mathrm{T}^{\prime}} / D_{\mathrm{SL}} \text { predicted } \\
\text { (Monte Carlo) }\end{array}$ \\
\hline Fig. 3 & $0.31 / \mathrm{km}$ & $1.28 \mathrm{~km}$ & $1.08 \pm 0.07$ & 1.10 \\
Fig. 4 & $0.65 / \mathrm{km}$ & $1.54 \mathrm{~km}$ & $1.16 \pm 0.09$ & 1.45 \\
Fig. 5 & $1.06 / \mathrm{km}$ & $1.56 \mathrm{~km}$ & $1.71 \pm 0.4$ & 1.80 \\
\hline
\end{tabular}




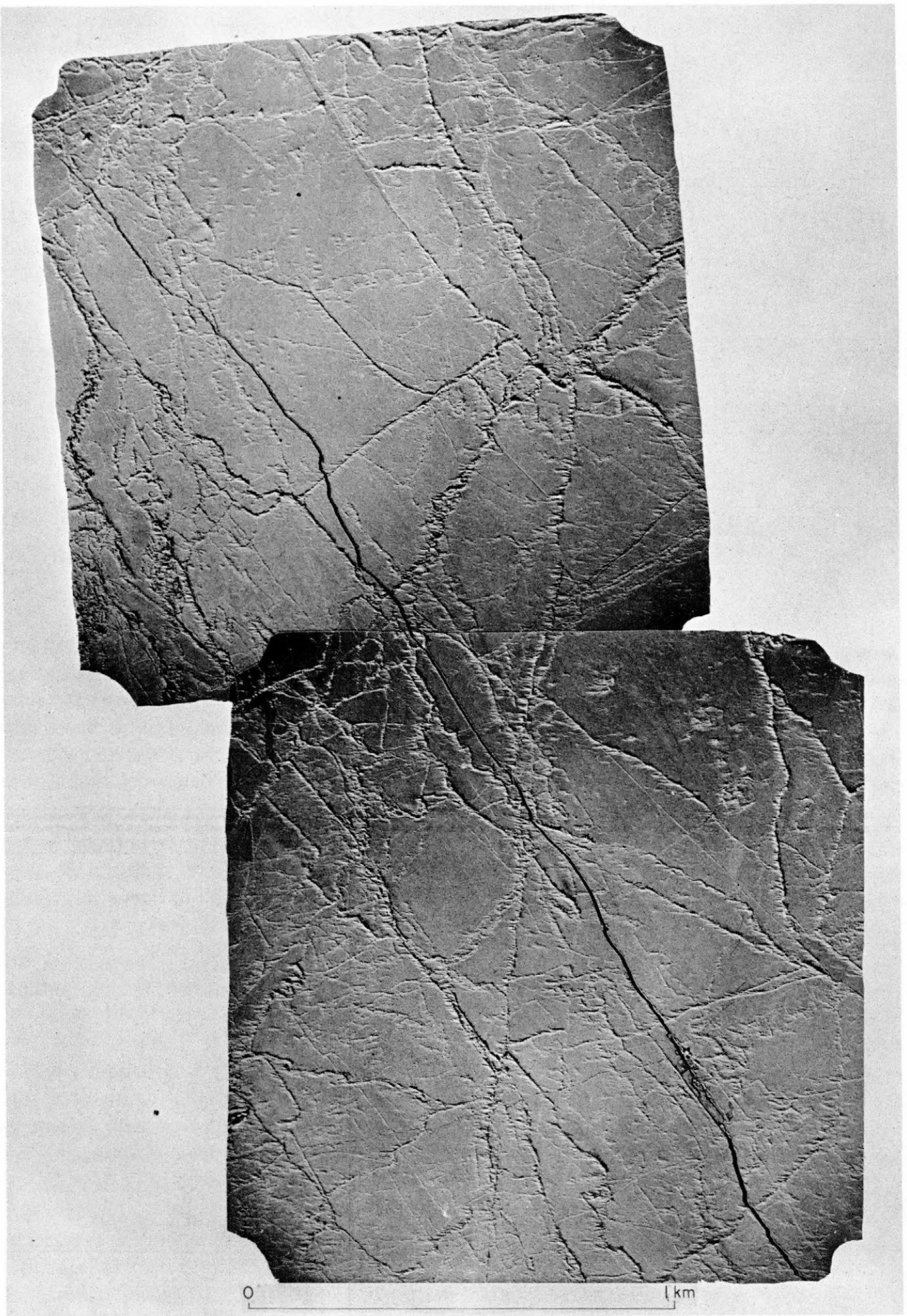

Figure 6. Vertical aerial view of sea ice showing the intersecting nature of ridges. Obtained over the Beaufort Sea by NASA, March 1971. 
These ridge overlays also give a perspective on the nature of terrain for different ridge frequencies. Of the three overlays, Figure 5 with a ridge frequency of about 1 ridge $/ \mathrm{km}$ shows the most dense array of ridges and, as is apparent, transit across such a region would not be rapid. However, on the scale of ridge frequencies encountered in the Arctic, as discussed in the next section, there are often more than 5 ridges $/ \mathrm{km}$ above $4 \mathrm{ft}$ high so that $1 \mathrm{ridge} / \mathrm{km}$ is not a heavy ridging. The terrain in Figure 3, on the other hand, with a ridge frequency of about $0.3 \mathrm{ridges} / \mathrm{km}$ begins to approach a terrain that can be rapidly moved over, although even in this case some maneuvering would be necessary. Generally, it appears that for rapid transit there must be fewer than 0.5 impassable ridges $/ \mathrm{km}$.

A further example illustrating the nature of the sea ice terrain is given in Figure 6, which shows a vertical aerial photo of ridging taken in the Beaufort Sea from an altitude of $3500 \mathrm{ft}$. This is a relatively lightly ridged area of the Arctic Ocean, as discussed in the next section. The photos illustrate again the intersecting nature of the ridging and reinforce the conclusion that ridge intersections are important obstacles for vehicles that cannot travel over most of the ridges encountered.

\section{Regional Variations in Ridging Intensity}

In order to estimate ease of travel in different regions of the Arctic Basin, using the above trafficability analysis, it is necessary to estimate the regional variability of $\mu_{\mathrm{h}}$, the number of ridges above height $h$. The regional, seasonal and annual variations of ridging intensity have been the subject of considerable study; a more detailed quantitative discussion of such variations based upon over $3000 \mathrm{~km}$ of laser profile data taken in different years and seasons is given by Hibler et al. (in prep). The results of these studies of variations indicate that from November through March the overall regional ridging variations may be approximately categorized. Figure 7 shows the results of such a categorization in terms of the number of ridges above given heights of $>4 \mathrm{ft},>6 \mathrm{ft},>8 \mathrm{ft}$ and $>10 \mathrm{ft}$. Since there is some variation in mean ridge heights from year to year, although the relative regional variations are similar, these heights may have about a 1-ft uncertainty. For a year of heavy ridging, for example, the 4-ft category refers to the number of ridges above $5 \mathrm{ft}$ and for a year of light ridging the number of ridges above approximately $4 \mathrm{ft}$.

As can be seen from Figure 7, the western portion of the Arctic Basin is divided into three ridging zones which are in order of decreasing ridge heights: 1) the offshore zone, consisting of the region off the Canadian Archipelago and Greenland; 2) the central arctic zone; and 3) the Beaufort Sea zone. Note that there is also an Alaskan zone, which includes the thin region off Alaska and the Canadian Northwest Territory, where shearing of the ice pack against the stationary shore ice produces a relatively narrow region of heavier ridging before the more lightly ridged Beaufort Sea zone is reached. This shear zone tends to be quite variable but in terms of ridge heights seems to have ridge heights similar to or higher than those of the offshore zone. Other aspects of the shear zone are discussed in the next section.

There is some difference in the morphology of ridges in the different regions. The central arctic zone has more multiyear ridges which have relatively smooth, rounded surfaces than the other zones, whereas the other zones contain many first-year ridges which are rough, often consisting of angular, jumbled blocks. A more detailed discussion of ridge structures is given by Weeks et al. (1971). To convey more clearly the nature of different ridges, several ground views of various ridges are shown in Figures 8-10. Figure 8 shows a multiyear ridge about $7 \mathrm{ft}$ high which is rather smooth and would be relatively easy to cross. Figure 9 shows a small first-year ridge about $5 \mathrm{ft}$ high and Figure 10 shows a first-year ridge 7-8 ft high. Clearly the rough angular nature of firstyear ridges makes them more difficult to clear than multiyear ridges. 


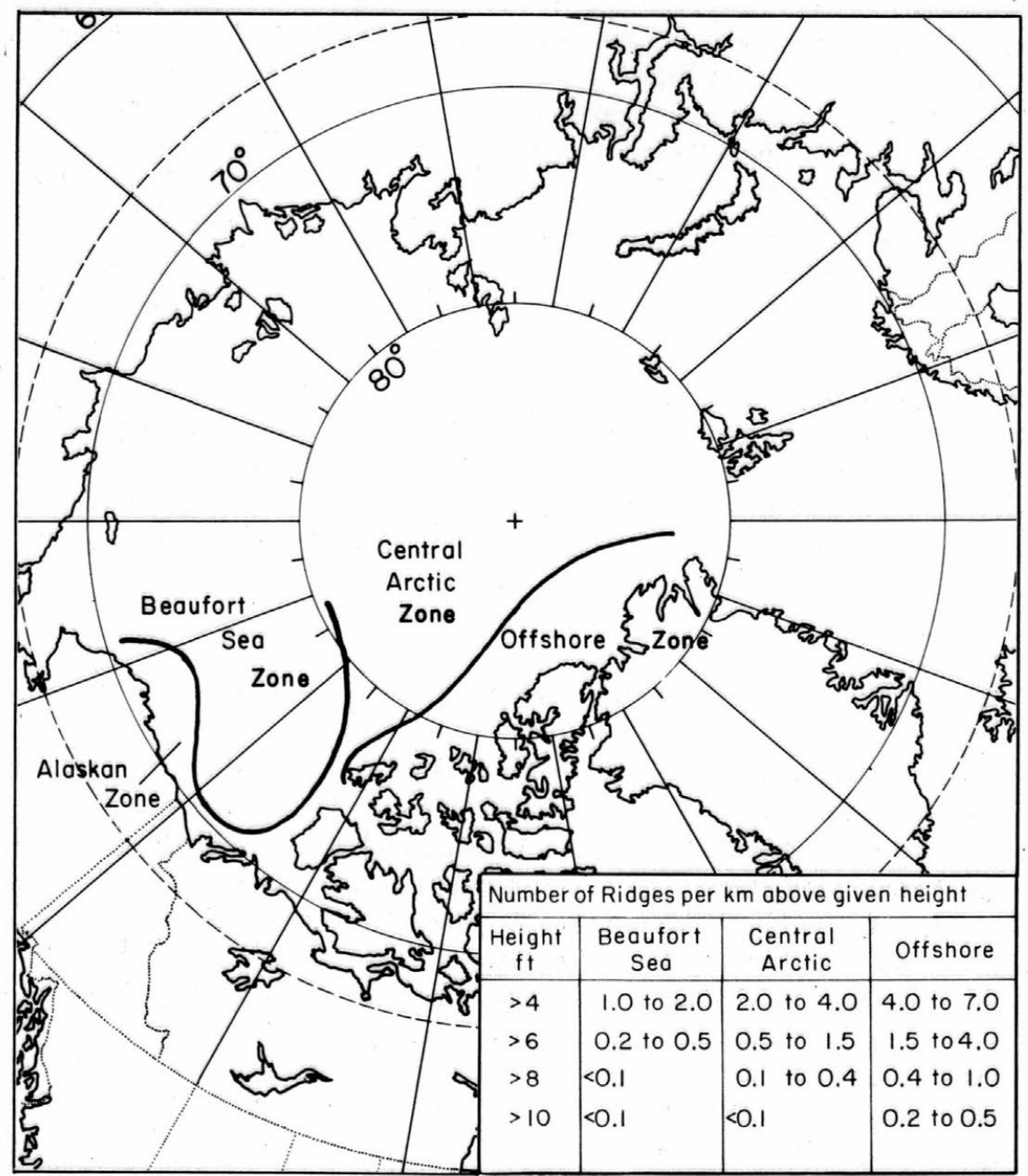

Figure 7. Regional variation of ridging in the Arctic Basin, given in terms of number of ridges per kilometer above different heights.

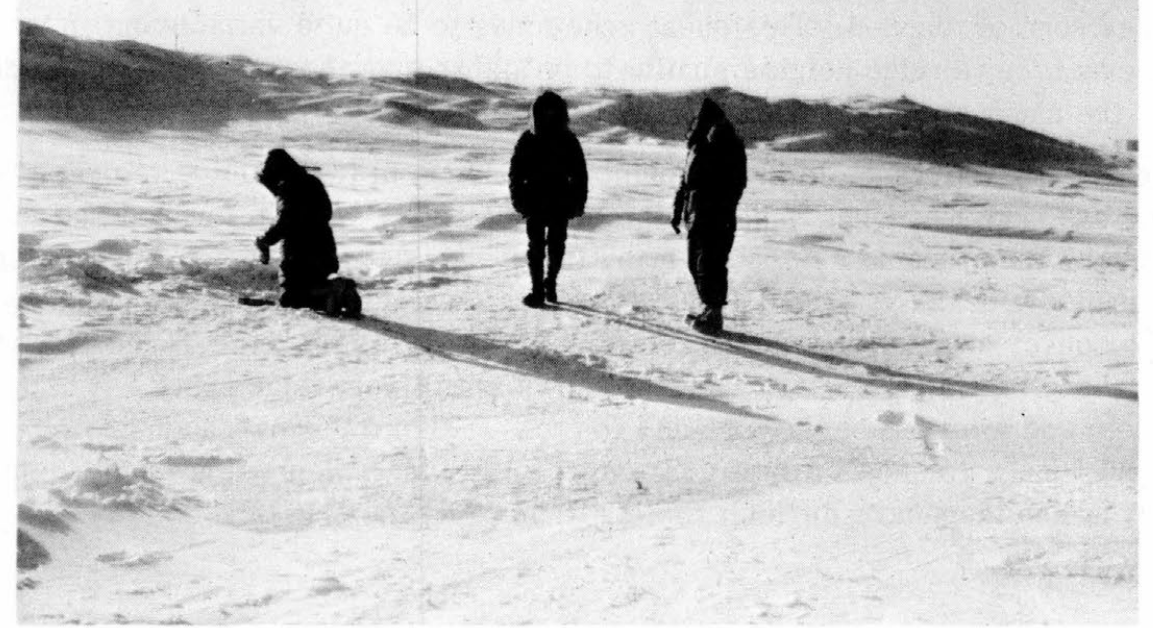

Figure 8. Multiyear approximately 7-ft-high ridge in the Beaufort Sea. 


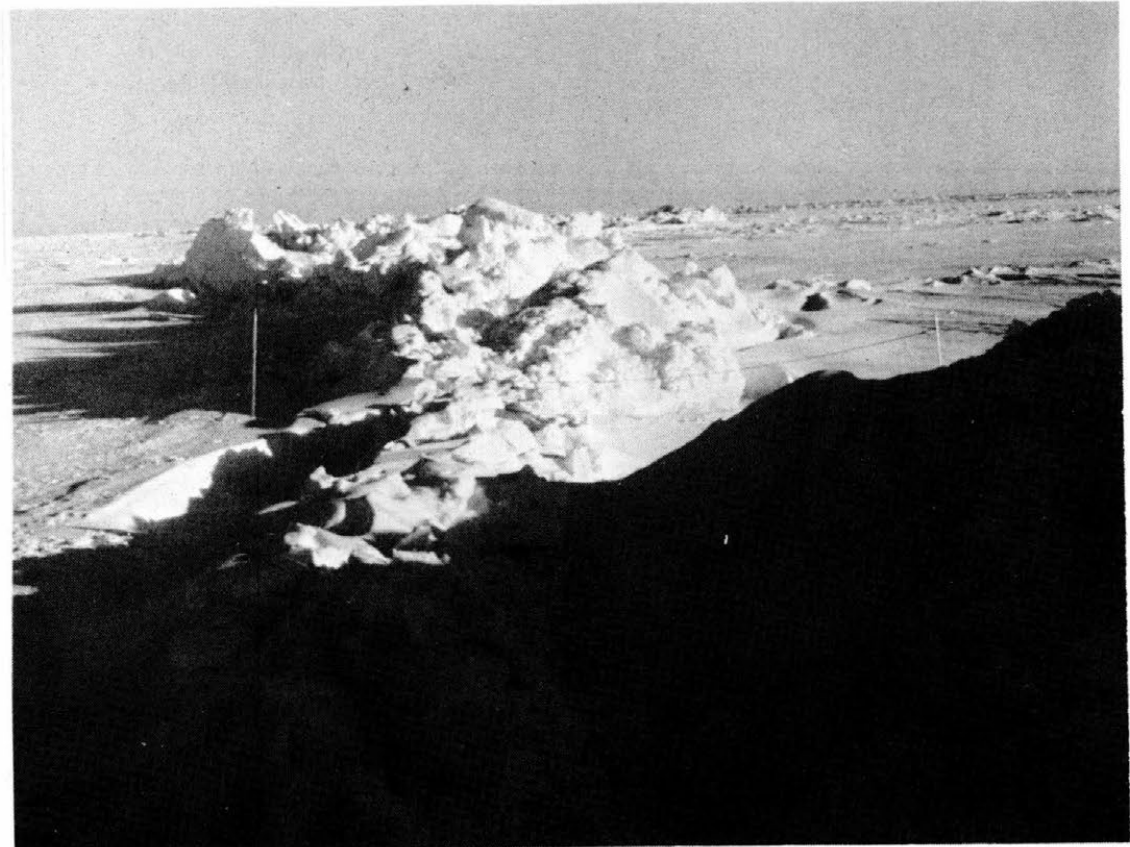

Figure 9. Small first-year ( $\sim$-ft-high) ridge in the Beaufort Sea.

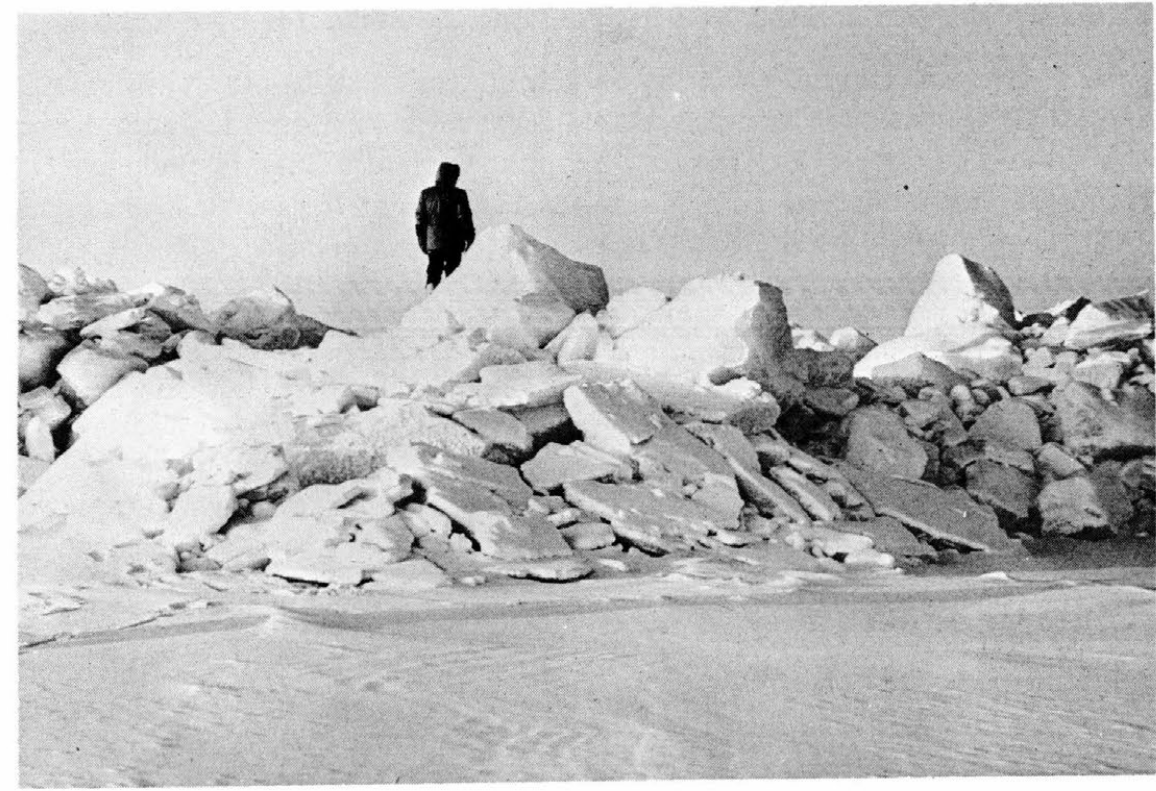

Figure 10. First-year (7 to 8-ft-high) ridge in the Beaufort Sea. 


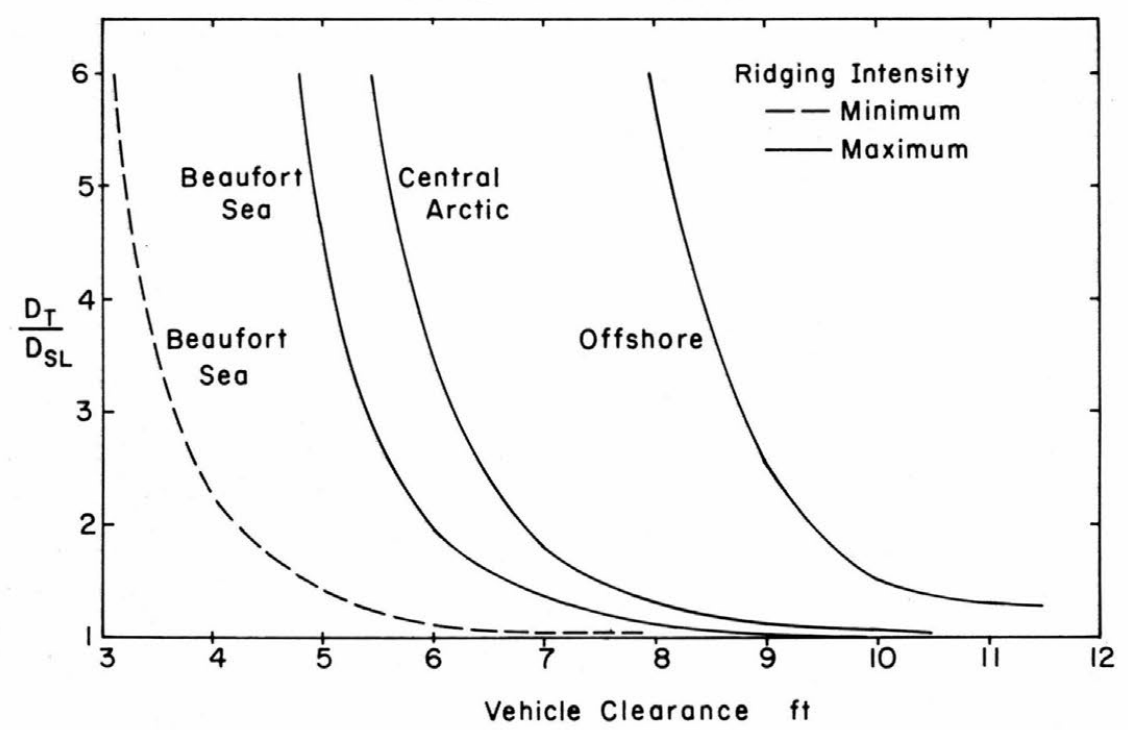

Figure 11. Trafficability ratio $D_{\mathrm{T}} / D_{\mathrm{SL}}$ as a function of vehicle clearance ability for various zones of the Arctic Basin. The solid curves were calculated for the maximum ridging intensity encountered in the various regions. The dashed curve was calculated for the minimum ridging intensity encountered in the Arctic Basin (Beaufort Sea).

It is clear from the ridging variations shown in Figure 7 that design for a vehicle operating off Alaska in the Beaufort Sea, and perhaps in the central Arctic, might be considerably different from that for a vehicle meant to operate everywhere in the Arctic. A vehicle having the ability to clear 5 to 6-ft ridges, for example, could travel reasonably well in the Beaufort Sea, but would have considerably decreased mobility in other zones, including the shear zone off Alaska.

The effect of regional ridging variation on vehicle trafficability is shown more clearly in Figure 11, which shows trafficability ratios as a lunction of vehicle clearance height for various ridging intensities. The curves are obtained by using typical values of the mean ridge height and frequency of ridges above $2 \mathrm{ft}$ high to evaluate the height distribution function given in eq 1. The number of ridges above a given height is then calculated and trafficability ratios are taken from Figure 2 using $\left\langle L^{2}\right\rangle /\langle L\rangle=1.5 \mathrm{~km}$. The solid curves were obtained using the parameter for the most intense ridging found from laser statistics for a given region. The dashed line was calculated using parameters obtained for the least intense ridging in the Beaufort Sea. The curves indicate the sharp increase in the trafficability ratio for a given region as the height clearance is decreased.

\section{Additional Trafficability Aspects of Sea Ice}

There are several further aspects of the arctic pack ice that relate to trafficability. Two such aspects are 1) the shear zone, with its concomitant rubble and hummock fields, where the pack ice meets the stationary shore-fast ice; and 2) long linear leads due to wind driven dilation of the ice pack.

\section{Shear zone and rubble fields}

Often in the shear zone constant grinding of the pack ice produces a dense collection of rough ice blocks and hummocks. This can also happen in localized regions elsewhere in the Arctic. An oblique aerial view of the shear zone is given in Figure 12. In extreme cases of this type of grinding 


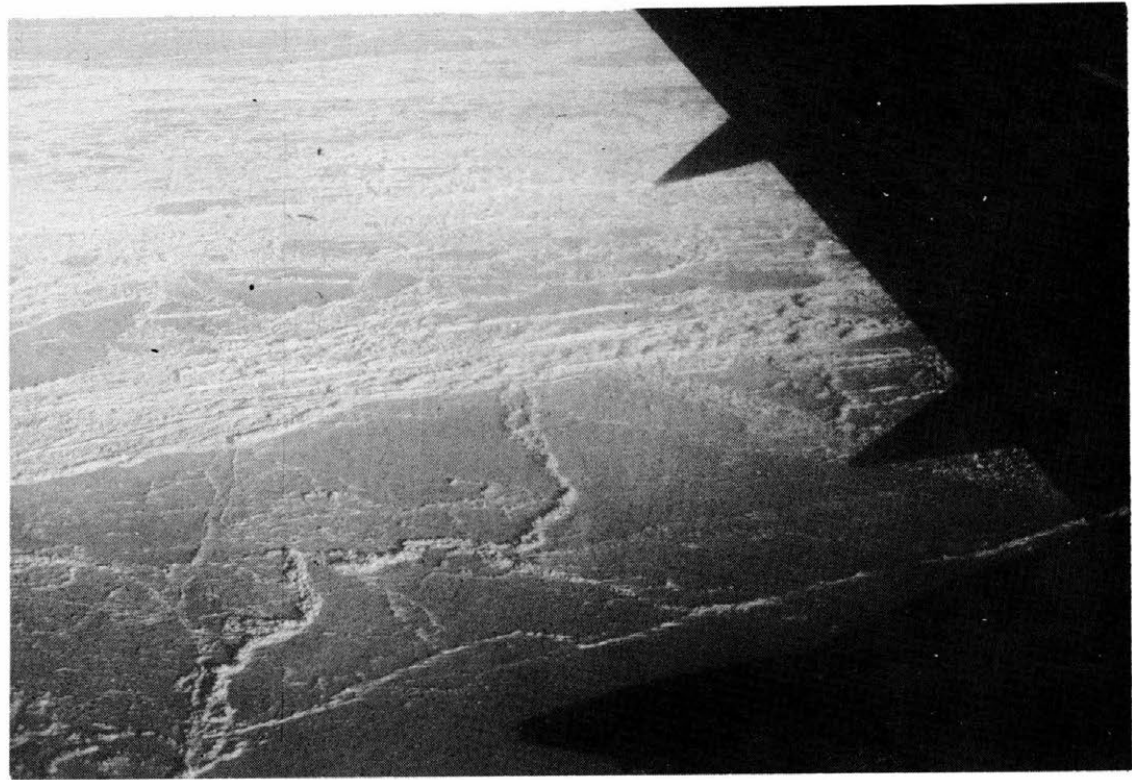

Figure 12. Oblique aerial view of the shear zone off Barrow, Alaska.

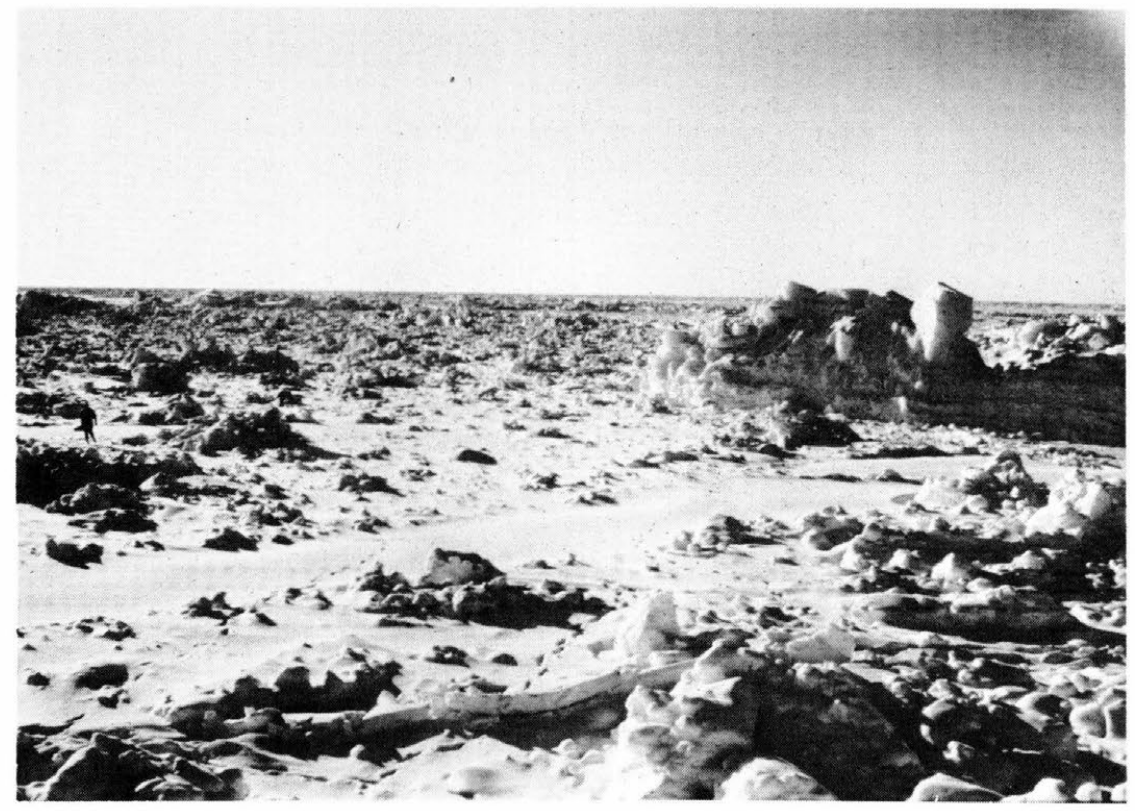

Figure 13. Closeup view of a rubble field in the Beaufort Sea.

and ridging, as discussed by Kovacs (1971), a series of quite high (several meters) closely spaced hummocks or ridges forms that looks like a farmer's plowed field. In less intense cases, the ice simply forms a series of jumbled blocks, sometimes with large, discontinuous, vertical faced ridges, as shown in Figure 13. Figure 13 gives a closeup of a rubble field; although the heights of the blocks are not great the rough surface may offer considerable hazard to certain types of vehicles. A descriptive account of travel through this zone by foot is given by Herbert (1970).

For classification, the shear zone generally is expected to have considerable rubble but may not always have extremely high ridges, especially not at all locations. Consequently, as a 


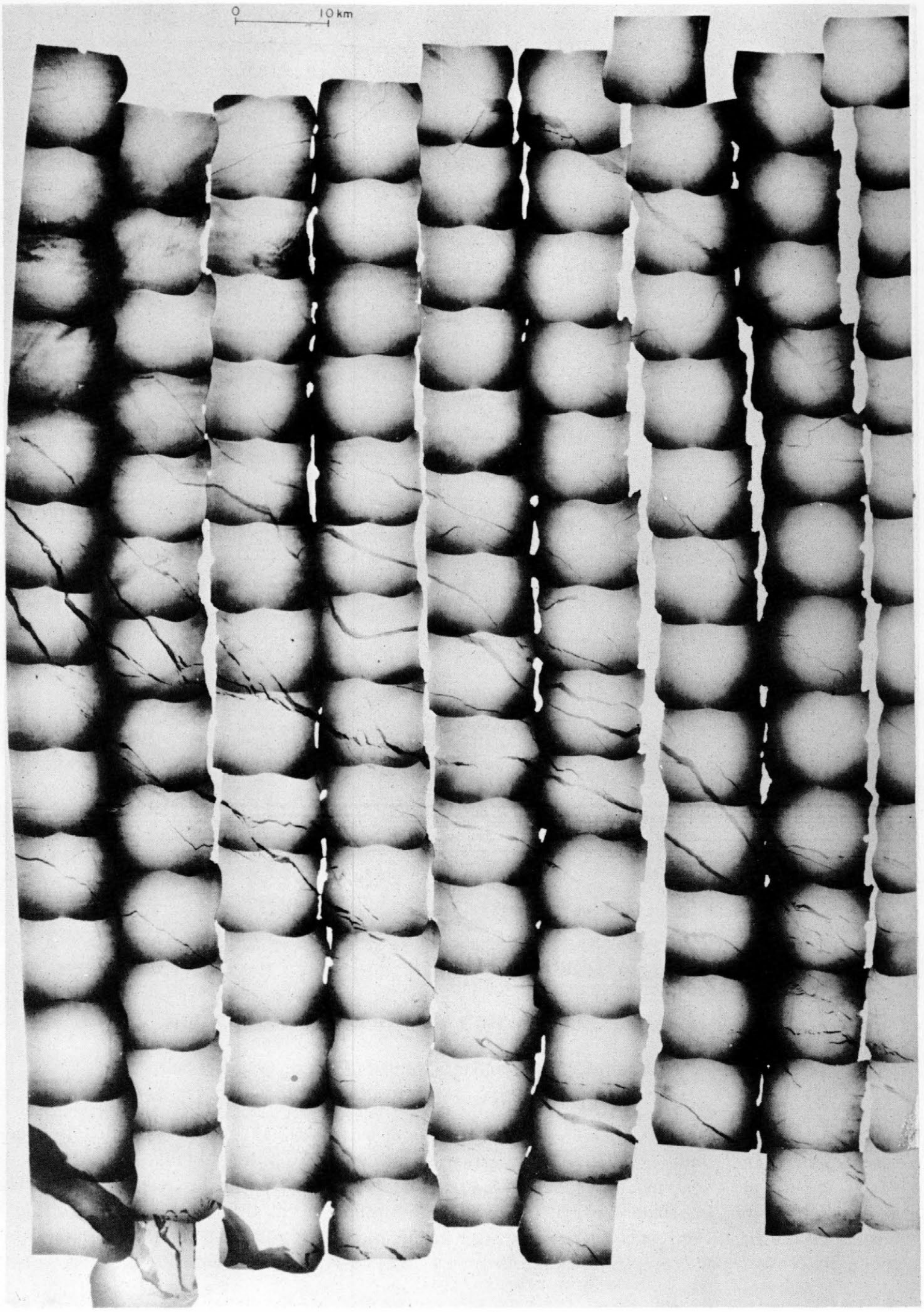

Figure 14. Aerial photo of typical linear lead system in sea ice. 
trafficability problem the shear zone can be considered a relatively thin but formidable barrier with the ridging intensity lalling off farther into the Arctic Ocean away from the shear zone. For detailed routing studies, the shear zone merits considerably more study.

\section{Linear lead systems}

As opposed to most aspects of sea ice terrain discussed above, linear lead systems tend to aid amphibious travel, at least in one direction, rather than impede it. Studies of sea ice drift and deformation to date (Hibler et al. 1973, Hibler 1973) generally indicate that during winter in a high pressure region the ice pack tends to open up. A typical lead system present under such a dilation is shown in Figure 14. The larger leads shown are as wide as $500 \mathrm{~m}$ and extend a considerable distance. The availability of these lead systems varies with the weather system, and studies are presently underway to predict their occurrence from meterological data.

Clearly, if one were interested in traveling parallel to a lead system, much more rapid vehicle progress could be made than normal. Also, since in winter such systems tend to form in high pressure regions with acoompanying good weather, visibility would be expected to be better than normal.

\section{Conclusions}

The study of sea ice terrain and the formulation of a trafficability model indicate that intersections of pressure ridges make travel over the pack ice by a sizeable (width several meters or larger) vehicle difficult when the vehicle cannot clear most pressure ridges encountered. If there are more than about 0.5 impassable ridges $/ \mathrm{km}$, rapid travel with a sizeable vehicle becomes difficult and, if there are more than 3 impassable ridges $/ \mathrm{km}$, any sort of travel with a sizeable vehicle becomes very difficult.

Using these numbers, the general statistical nature of arctic pressure ridges indicates that a vehicle's capability of clearing 5 to 6-ft ridges is a minimal requirement for travel in the Beaufort Sea and central arctic regions, and of clearing 8- to 9-ft ridges is a minimal requirement for the offshore zone off the Canadian Archipelago.

In addition to pressure ridging in the Arctic Basin, the shear zone off Alaska and the Canadian Northwest Territory, with its rubble and hummock fields in many locations, forms a-thin but very rugged barrier, although one could probably cross this barrier in a vehicle by carefully searching for an opening in the barrier.

One possible exception to the trafficability model based upon ridges may occur when long linear leads form during dilation of the pack ice in high pressure regions in winter. These leads often form in parallel patterns and may supply rapid transit zones in one direction for vehicles which otherwise would be forced to move slowly through the pressure ridges.

\section{Literature Cited}

Aerojet-General Corp. (1972) Arctic surface effect vehicle program. Quarterly Progress Report AGC-T-306.

Bekker, M.G. (1969) Introduction to terrain vehicle systems. Ann Arbor: University of Michigan Press, p. 191-192.

Cartwright, D.E. (1962) Waves. In The sea, Chap. 5 (M.N. Hill, Ed.). Physical Oceanography, vol. 1, Interscience Publication. 


\section{Literature Cited (cont'd)}

Grumman Aerospace Corp. (1972) Arctic surface effects vehicle program. Final Report PDR- 579-75.

Herbert, W. (1970) The first surface crossing of the Arctic Ocean. Geographical Journal, vol. 136, pt. 4, p. 511-533.

Hibler, W.D. III (1971) Two dimensional statistical analysis of arctic sea ice ridges. Proceedings of the International Sea Ice Conference, Reykjavik.

Hibler, W.D. III (1972) Removal of aircraft altitude variation from laser profiles of the arctic ice pack. Journal of Geophysical Research, vol. 77, no. 36, p. 7190-7197.

Hibler, W.D. III (1973) Differential sea ice drift, II: Comparison of mesoscale strain measurements to linear drift theory predictions. AIDJEX Bulletin No. 21, p. 115-139. (Also to be published in Journal of Glaciology.)

Hibler, W.D. III and S.F. Ackley (1973) Height variation along sea ice pressure ridges and the probability of finding "holes" for vehicle crossings. U.S. Army Cold Regions Research and Engineering Laboratory (USA CRREL) Special Report.

Hibler, W.D. III and S.J. Mock (1971) Interim sea ice statistics. USA CRREL SEV Report 1.

Hibler, W.D. III, S.J. Mock and W. Tucker (in prep) Classification and variation of sea ice ridging in the Arctic Basin. (Submitted to Journal of Geophysical Research.)

Hibler, W.D. III, W.F. Weeks, S.F. Ackley, A. Kovacs and W.J. Campbell (1973) Mesoscale strain measurements on the Beaufort Sea pack ice. Journal of Glaciology, vol. 12, no. 65 , p. $187-207$.

Hibler, W.D. III, W.F. Weeks and S.J. Mock (1972) Statistical aspects of sea ice ridge distributions. Journal of Geophysical Research, vol. 77, no. 30, p. 5954-5970.

Kovacs, A. (1971) On pressured sea ice. Proceedings of International Sea Ice Conference, Reykjavik.

LeSchack, L.A. and J.B. Long (1972) Examining some design parameters for arctic surface effect vehicles by means of airborne laser profilometry. Hovering craft and hydrofoil, vol. 11 , no. 12 .

Mock, S.J., A. Hartwell and W.D. Hibler III (1972) Spatial aspects of pressure ridge statistics. Journal of Geophysical Research, vol. 77, no. 30, p. 5945-5953.

Smith, M. and Y. Nakano,(1978) Model analysis of vehicle trafficability with application to surface effect vehicles on sea ice fields. Journal of Terramechanics, vol. 9, no. 2.

Weeks, W.F., A. Kovacs and W.D. Hibler III (1971) Pressure ridge characteristics in the arctic coastal environment. Proceedings on the 1st International Conference on Port and Ocean Engineering under Arctic Conditions, Technical University of Norway. 


\section{APPENDIX A. DISTRIBUTION OF THE LATERAL EXTENT OF RIDGES}

Ridge lengths are a somewhat difficult parameter to estimate for a number of reasons. One of the primary reasons is that the nature of the distribution of ridge lengths makes it necessary to sample a relatively large area (tens to hundreds of square kilometers). Since ridges are relatively low relief features ( $<15$ to $20 \mathrm{ft}$ high), aerial photography, the primary source of data for this type of information, must be obtained at low altitudes $(<10,000 \mathrm{ft})$ in order to adequately resolve these features. However, the cameras must not be flown so low that the area covered is not a large enough sample; so a trade-off between obtaining photography that adequately resolves ridges and sampling a sufficiently large region to be statistically valid must be achieved. It is also necessary to use photo mosaics, since ridges generally extend beyond the region sampled by one aerial photograph. This constraint also limits the study to two specific areas since photo mosaics at low level on sea ice are not generally available.

Once adequate data are available, some subjective judgments must then be applied to obtain the ridge length distributions. The first concerns the definition of the height cutoff. Low ridges $(<3 \mathrm{ft})$ are generally subdued by snowdrifting and other relief changes, so they are much harder to distinguish than high ridges $(>5 \mathrm{ft})$. Also, since it is generally agreed that vehicles should be able to traverse "low" objects, and the purpose of this study was to obtain a length distribution for ridges considered difficult or impossible to cross, the following semiempirical criteria were used to define ridges: 1) Ridges were used in the distribution if they were greater than $\sim 5$ feet high, based on comparison of known areas from ground measurements with the same areas portrayed on the aerial photographs; 2) Ridges were considered to end when the height level dropped into a "low" category (estimated to be below $3 \mathrm{ft}$ ) and this low category persisted for a minimum of $100 \mathrm{~m}$ $(328 \mathrm{ft})$. Each continuous segment defined in this manner was called a ridge and its length was measured at the appropriate scale.

Using the above criteria, ridge overlays of two photo mosaics were prepared. These overlays are shown in Figures 3 and 4 in the main text. The distribution of the ridge lengths and other length statistics are given in Figures A1 and A2. As can be seen, the values of $\left\langle L^{2}\right\rangle \mid\langle L\rangle$ are of the order of 1.2 to $1.5 \mathrm{~km}$, with the shape of the distribution tending toward a negative exponential. Fitting a negative exponential distribution (of the form $N \mu \exp (-\mu \mathrm{x})$, where $\mu=1 /\langle L\rangle$ and $N$ is the number of ridges) to the observed distribution, the $\chi^{2}$ totals were within the $5 \%$ confidence limits in both cases. A negative exponential is physically reasonable for ridge lengths since it can be derived, for example, by assuming that openings in ridges occur randomly so that spacing between holes is exponentially distributed (for example, see Hibler et al. 1972). We note in passing that for a negative exponential distribution $\left\langle L^{2}\right\rangle /\langle L\rangle$ is equal to $2\langle L\rangle$.

For generalization of these ridge length distributions to either higher $(>\sim 5 \mathrm{ft})$ or lower $(<3 \mathrm{ft})$ ridges, examination of available aerial photographs and field observations suggests that the mean ridge length increases slightly with increasing height, and may, for example, be of the order of $2 \mathrm{~km}$ for 8 to 9 -ft ridges and $1 \mathrm{~km}$ for 3 to 4 -ft ridges. 

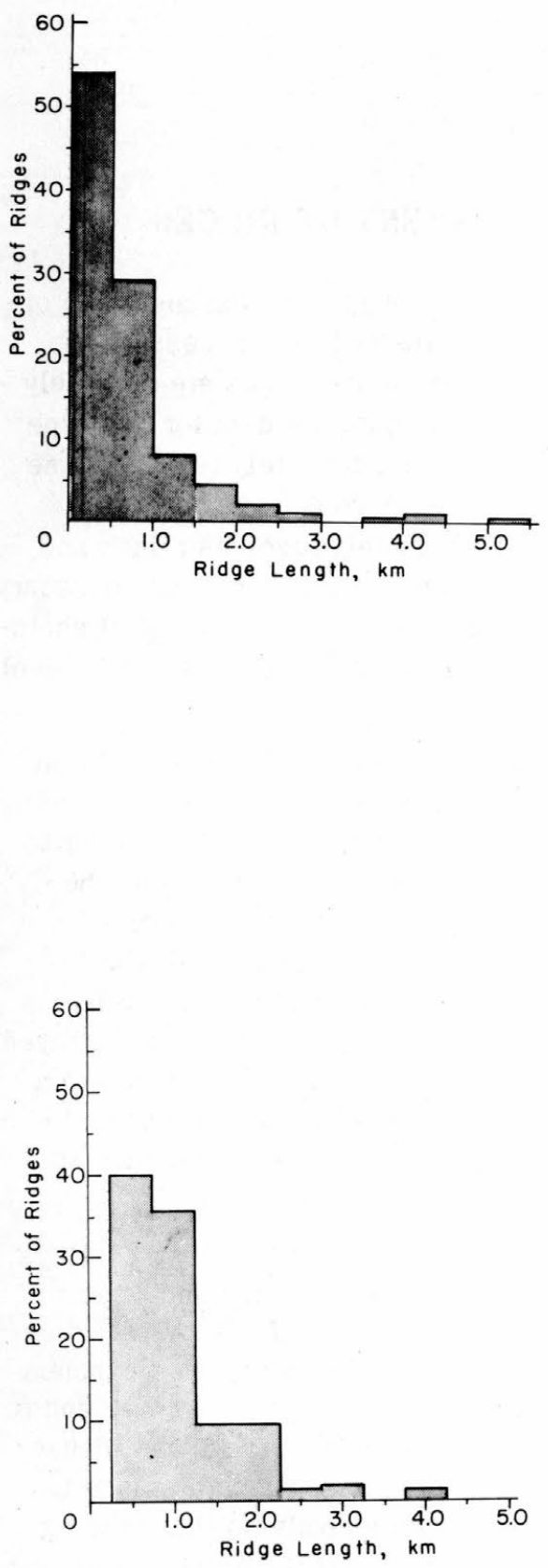

Figure A1. Data obtained from aerial photo mosaic taken at $75^{\circ} \mathrm{N}, 145^{\circ} \mathrm{W}$ in the Beaufort Sea [site of the March-April 1972 AIDJEX camp (Fig. 3).] Area sampled was $441 \mathrm{~km}^{2}$ and total number of ridges was 307. Mean ridge length $\langle L\rangle=0.635 \mathrm{~km}$. Mean square length $\left\langle L^{2}\right\rangle=0.816 \mathrm{~km}^{2}$. Variance $=0.413 \mathrm{~km}^{2} .\left\langle L^{2}\right\rangle t\langle L\rangle=1.28 \mathrm{~km}$. No. of ridges $/$ unit length $(>5 \mathrm{ft})=0.31 / \mathrm{km}$.
Figure A2. Data obtained from aerial photo mosaic taken at $74^{\circ} \mathrm{N}, 131^{\circ} \mathrm{W}$ in the Beaufort Sea [site of the March 1971 AIDJEX camp (Fig. 4)]. Area sampled was $332 \mathrm{~km}^{2}$ and total number of ridges was 180 . Mean ridge length $\langle L\rangle=$ $1.02 \mathrm{~km}$. Mean square length $\left\langle L^{2}\right\rangle=1.57 \mathrm{~km}^{2}$. Variance $=0.536 \mathrm{~km}^{2} .\left\langle L^{2}\right\rangle /\langle L\rangle=1.54 \mathrm{~km}$. No. of ridges/unit length $(>5 \mathrm{ft})=0.65 / \mathrm{km}$. Because of the height of the photography, ridge lengths shorter than $0.25 \mathrm{~km}$ were not included in the distribution, as shown in the figure. 


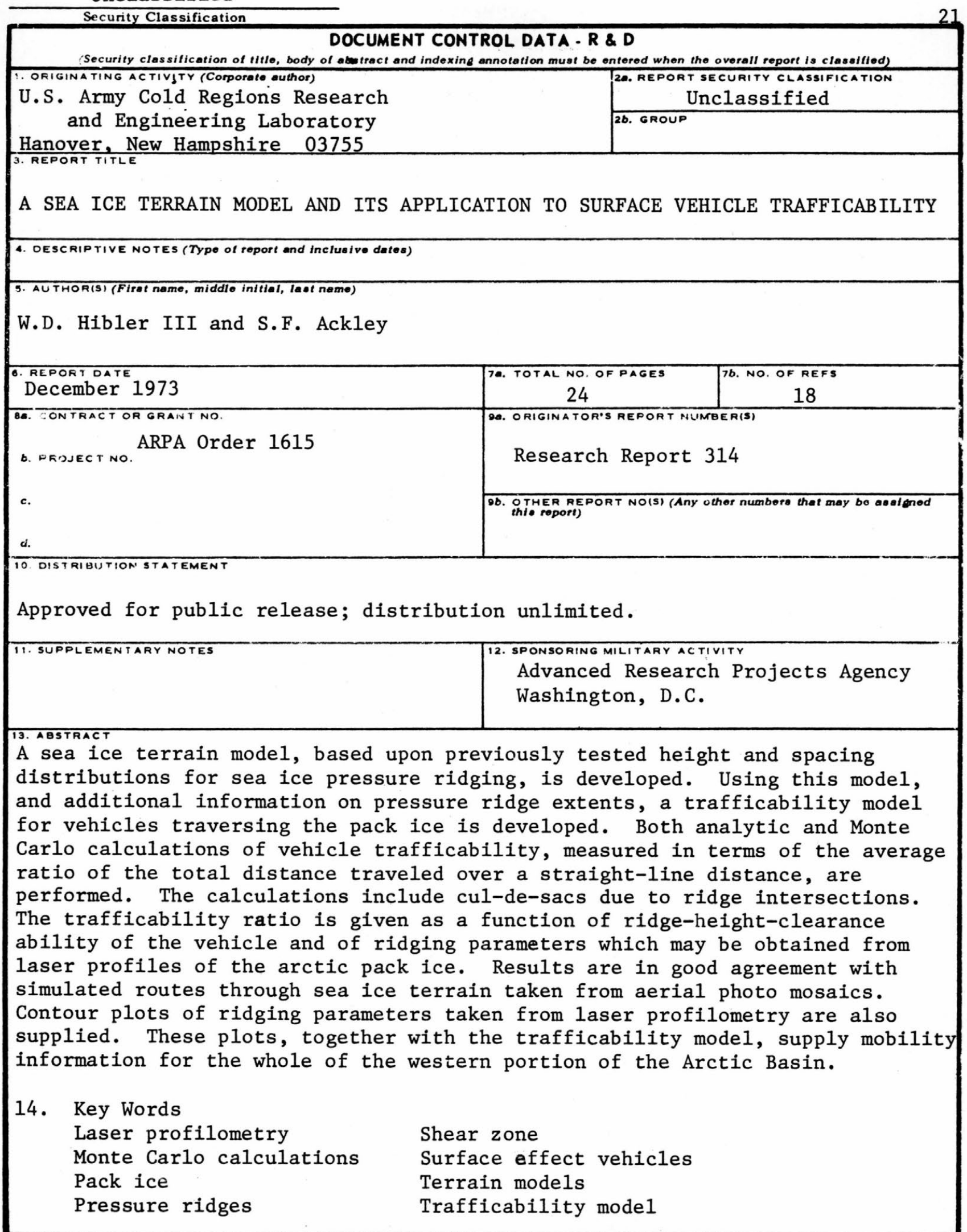

